\title{
O TRATAMENTO DO ESPORTE COMO CURRÍCULO NO CURSO DE GRADUAÇÃO EM EDUCAÇÃO FÍSICA
}

\author{
Edson Costa Farret \\ Instituto Federal do Rio de Janeiro, São Gonçalo, Rio de Janeiro, Brasil \\ Dinah Vasconcellos Terra \\ Universidade Federal Fluminense, Niterói, Rio de Janeiro, Brasil \\ Carlos Alberto Figueiredo \\ Universidade Salgado de Oliveira, Niterói, Rio de Janeiro, Brasil
}

\begin{abstract}
Resumo
Este estudo tem por objetivo investigar, através de uma revisão de literatura, como o esporte é tratado como conteúdo nos cursos de graduação em Educação Física. A metodologia utilizada é de perspectiva qualitativa com caráter bibliográfico que, segundo Gil (1995), envolve entre outros elementos o levantamento bibliográfico e documental. Dos estudos selecionados, todos apontam para superação à denominada "esportivização" do currículo. Assim, este estudo se justifica por contribuir com a prática pedagógica do esporte no ensino superior. Percebemos que novas estratégias de ensinar o esporte vem surgindo, na perspectiva de construir uma identidade no trato do esporte no ensino superior, buscando uma formação mais reflexiva dos acadêmicos em Educação Física.
\end{abstract}

Palavras-chave: Esporte. Currículo. Formação inicial.

\section{Introdução}

As reflexões apresentadas neste trabalho fazem parte dos estudos da dissertação no Programa de Mestrado em Ciências da Atividade Física na Universidade Salgado de Oliveira que tem como objetivo investigar, como o esporte é tratado como conteúdo curricular nos cursos de graduação em Educação Física.

A metodologia utilizada, para organização do texto, é de perspectiva qualitativa. Os instrumentos para obtenção dos dados serão aqueles pertinentes aos estudos qualitativos de caráter bibliográfico que segundo Gil (1995), envolvem entre outros elementos o levantamento bibliográfico e documental.

Os estudos que discutem sobre o esporte como currículo na formação superior na área de Educação Física é um assunto que vem sendo apresentado mais intensamente a partir da década de 1980. Podemos destacar os trabalhos de Oliveira (1989); Molina Neto(1995, 2000); Pirolo e Terra (1997); Moreno (1998); Melo (2002); Gonzales (2004, 2009); Pires e Neves (2002); Nascimento (2009); Colavolpe (2005, 2010); Rezer (2009); Alviano Jr. (2011); Santos (2011) entre outros. Desses estudos citados, todos apontam para superação à denominada "esportivização" do currículo, sendo que alguns apresentam em seus escritos (além de uma revisão teórica crítica) discussões com propostas de experiências pedagógicas exitosas com destaque para algum esporte específico (handebol, vôlei ou basquete), já outros são desenvolvidos com ênfase no campo teórico. 
Desta forma, o texto busca contribuir na discussão do ensino do esporte nos cursos de formação de professores em educação física.

\section{Propostas curriculares nos cursos de graduação em educação física: uma abordagem histórica}

Antes de iniciarmos a análise proposta pelo estudo, consideramos importante abordar as mudanças que ocorreram no currículo do curso em graduação em Educação Física no Brasil.

Vivemos numa sociedade onde mudanças de paradigmas ocorrem a todo instante. Tais mudanças influenciam na formação humana exigindo mudanças na qualidade de serviço, na formação continuada, criando uma adaptação ao novo, à criatividade, à iniciativa e à cooperação. Assim, os profissionais que buscam adequar-se a estas novas exigências, internalizam a necessidade pela busca constante do conhecimento e por nova formação (GENTILLI, 2000).

Nesse contexto de mudanças em todos os setores sociais, a educação básica e o ensino superior acabam sendo utilizados como instrumentos capazes de adequar a sociedade às novas exigências do mundo globalizado. (FRIGOTTO, 1998).

Assim, os conteúdos curriculares e o modo como são aplicados, influenciam diretamente o perfil de aluno, de escola, de sociedade e de mundo que queremos. Numa perspectiva educacional, currículo é reconhecido tradicionalmente como um conjunto de disciplinas organizadas numa sequencia lógica podendo sofrer alterações no decorrer do tempo.

Compreender que as mudanças no currículo sempre estarão atreladas às conjunturas, aos avanços políticos, à reflexões e práticas cotidianas dos profissionais de educação é algo que se faz sempre necessário. É nesta lógica de reflexão, ou seja, uma ação contínua de (re)significação na qual o melhor caminho a seguir (currículo), é que ocorrem as mudanças nos projetos curriculares, buscando um perfil de homem e de sociedade que acredita. É neste, que concordamos com a concepção de currículo de Silva, quando cita:

O currículo tem significados que vão muito além daqueles aos quais as teorias tradicionais nos confinaram. O currículo é lugar, espaço, território. O currículo é relação de poder. O currículo é trajetória, viagem, percurso. O currículo é autobiografia, nossa vida, curriculum vitae: no currículo se forja nossa identidade. $\mathrm{O}$ currículo é texto, discurso, documento. O currículo é documento de identidade (1999, p.150).

Partindo para o específico da Educação Física, compreendemos que os currículos dos cursos de ensino superior no Brasil foram influenciados por várias correntes de pensamentos que balizaram a construção dos currículos da Educação Física no país. Concordando com este pensamento, destacamos o estudo de Andrade Filho quando afirma:

[...] a formação profissional em seu desenrolar foi se comprometendo com objetivos sociais e de promoção de conhecimentos científicos ditados por outros segmentos profissionais, de fora pra dentro da área, desde o início. Objetivos sociais, como fortalecer a raça, modelar a personalidade do educando, esportivizar a sociedade, atender as demandas do mercado de serviços, transformar a realidade social, e/ou objetivos científicos, como experimentar/promover o uso em larga escala de exames biofisiológicos e a aplicação técnica didático-pedagógicas (escola novista, tecnicista, histórico-crítica) e de treinamento esportivo de rendimento são signos que, cada um a seu tempo, enredaram a área desde o começo (2001, p.35). 
Assim, as propostas curriculares adotadas ao longo do tempo pelos cursos de Educação Física foram direta ou indiretamente influenciadas pelas diferentes concepções, e por que não dizer diferentes documentos de identidades de Educação Física que foram se (re)estruturando ao longo do tempo.

Abordando sobre propostas curriculares nos cursos superiores em Educação Física, destacamos que a proposta curricular do curso superior em Educação Física, no Brasil, teve quatro reestruturações curriculares oficiais marcantes para se chegar ao que temos hoje (TREPTOW, 2008).

O primeiro marco foi a criação da Escola Nacional de Educação Física e Desportos (ENEFD), junto a Universidade do Brasil, atual Universidade Federal do Rio de Janeiro, pelo Decreto Lei n. ${ }^{\circ} 1212$, de 17 de abril de 1939. Prevalecia uma concepção de formação de professor como instrumento disciplinador e produtores de corpos produtivos a serviço da nação brasileira (TREPTOW, 2008).

O segundo modelo curricular foi definido com a Resolução do Conselho Federal de Educação n. ${ }^{\circ} 69$ de 6 de novembro de 1969, que determinava um currículo mínimo para os cursos de Educação Física. Criava a Licenciatura em Educação Física e mantinha o técnico em desporto, introduzindo as disciplinas pedagógicas comuns a todas as licenciaturas (de acordo com o Parecer CFE n. ${ }^{\circ}$ 672/69).

O terceiro modelo foi o instituído com o Parecer n. ${ }^{\circ}$ 215/87, pela Resolução CFE n. ${ }^{\circ}$ 03 de 16 de junho de 1987. Proporcionava a formação em Licenciatura e/ou Bacharelado; concedia flexibilidade e autonomia as IES para criarem seus currículos; e torna obrigatória a apresentação de uma monografia no final do curso de Bacharelado. O curso de Bacharelado buscava formar um profissional cujo campo de atuação é o ambiente não escolar, como clubes e academias e o curso de Licenciatura buscava formar um profissional qualificado para atuar no âmbito da Educação Física Escolar da educação infantil ao ensino médio (BENITES; NETO; HUNGER, 2008).

O quarto modelo curricular origina em três normativas: Resolução n. ${ }^{\circ}$ 01/2002 do CNE, que trata das diretrizes Curriculares para os cursos de formação de professores de Educação Básica em nível superior, com licenciatura plena, da Resolução n. ${ }^{\circ}$ 02/2002, que trata da duração e a carga horária dos cursos de formação de professores de Educação Básica em nível superior, e da Resolução CNE/CES n 07/2004, que instituiu as Diretrizes Curriculares para os cursos de Graduação em Educação Física (TREPTOW, 2008).

Benites e colaboradores (2008) destacam que, com a Resolução n 02/2002, o momento histórico é outro, passando por períodos de um engajamento, pelo menos no discurso, com o social. As políticas educacionais vão se configurar de forma a privilegiar a formação de um educador "competente" para estar apto a trabalhar no mercado de trabalho e, ao mesmo tempo, especialista em suas funções, sendo imprescindível para a sociedade. Neste momento, começa a passagem de um modelo abrangente com características próprias para um modelo de certificação em que as competências ganham um novo papel.

Na Educação Física, com a Resolução CNE/CES 7/2004, procurou-se "corrigir" alguns limites da Resolução CFE 03/87 em termos de definições, concepção do campo e organização curricular, buscando, inicialmente, delimitar o que se entende por Educação Física como uma área acadêmico-profissional.

Já 07/2004 e o parecer 058/2004 tratam das diretrizes curriculares para a graduação em Educação Física. Nesta lógica, os cursos buscam alterar suas estruturas curriculares devido às novas diretrizes curriculares para as licenciaturas e para os cursos de graduação em Educação Física, surgindo novas alternativas na reestruturação na elaboração das grades curriculares.

É a partir desta mudança estrutural que surgem algumas inquietações: qual o tratamento dado ao esporte no currículo do curso superior em Educação Física com as novas 
diretrizes curriculares? O que se tem produzido a este respeito? Em que as produções do conhecimento tem contribuído? Existem propostas de reestruturação na temática do esporte no currículo da graduação em Educação Física? Neste sentido, a revisão apresentada busca transcorrer por estas inquietações.

\section{Esporte e formação inicial no curso de educação física: uma revisão da literatura}

Dos estudos que buscam refletir sobre o trato do esporte como currículo na formação inicial, alguns buscam a superação à denominada "esportivização" do currículo. Partindo deste ponto é que elaboramos a seleção das dissertações e teses. A busca pela seleção desses estudos se baseou no banco de dados do Núcleo Brasileiro de Dissertações e Teses (NUTESES) (www.nuteses.ufu.br/) e a busca foi realizada em agosto de 2012. Num primeiro momento, realizamos um mapeamento para identificar os estudos que explicitavam essa intenção, através dos termos: esporte, currículo, licenciatura e formação inicial. Após esta ação, selecionamos os estudos para serem analisados.

Neste sentido, apresentamos um quadro com informações referentes a Dissertações e Teses que foram realizadas desde 1996 que tiveram o esporte na formação inicial como objeto de estudo.

Quadro 1 - Caracterização das Dissertações e Teses selecionadas

\begin{tabular}{|c|c|c|}
\hline AUTOR & TÍTULO & ANO \\
\hline $\begin{array}{l}\text { TERRA, Dinah } \\
\text { Vasconcellos }\end{array}$ & $\begin{array}{l}\text { Ensino crítico-participativo das } \\
\text { disciplinas técnico-desportivas nos cursos de } \\
\text { licenciatura em Educação Física: análise do } \\
\text { impacto de um projeto de ensino no } \\
\text { handebol. } \\
\text { Universidade Gama Filho, RJ. }\end{array}$ & 1996 \\
\hline $\begin{array}{l}\text { PIROLO, Alda } \\
\text { Lúcia }\end{array}$ & $\begin{array}{l}\text { A disciplina de voleibol nos cursos de } \\
\text { licenciatura em Educação Física do Paraná: } \\
\text { Processo de conhecimento crítico-reflexivo? } \\
\text { Universidade Gama Filho, RJ. }\end{array}$ & 1996 \\
\hline $\begin{array}{l}\text { MORENO, José } \\
\text { Carlos de } \\
\text { Almeida }\end{array}$ & $\begin{array}{l}\text { A disciplina Basquetebol e a Formação dos } \\
\text { Professores de educação Física. UNICAMP }\end{array}$ & 1998 \\
\hline $\begin{array}{l}\text { MELO, Fábio } \\
\text { Antonio Tenório } \\
\text { de }\end{array}$ & $\begin{array}{l}\text { O futsal como disciplina curricular nos } \\
\text { cursos de graduação em Educação Física, no } \\
\text { Distrito Federal. Faculdade de Educação } \\
\text { Física, Universidade Católica de Brasilia, } \\
\text { Brasília. }\end{array}$ & 2002 \\
\hline $\begin{array}{l}\text { COLAVOLPE, } \\
\text { Carlos Roberto }\end{array}$ & $\begin{array}{l}\text { O Esporte como conteúdo nos cursos } \\
\text { de formação de professores: realidade e } \\
\text { possibilidades. } \\
\text { Universidade Federal da Bahia. } \\
\text { Faculdade de Educação, Salvador. }\end{array}$ & 2005 \\
\hline $\begin{array}{l}\text { COLAVOLPE, } \\
\text { Carlos Roberto }\end{array}$ & $\begin{array}{l}\text { Sociedade, Educação e Esporte: A } \\
\text { Teoria do Conhecimento e o Esporte na } \\
\text { Formação de Professores de Educação } \\
\text { Física } \\
\text { Universidade Federal da Bahia. }\end{array}$ & 2010 \\
\hline
\end{tabular}




\begin{tabular}{|l|l|l|}
\hline & Faculdade de Educação, Salvador. & \\
\hline $\begin{array}{l}\text { ALVIANO JR., } \\
\text { Wilson }\end{array}$ & $\begin{array}{l}\text { Conhecimento e aplicação de Métodos de } \\
\text { Ensino para os Jogos Esportivos Coletivos } \\
\text { na Formação Profissional em Educação } \\
\text { Física } \\
\text { Universidade São Judas Tadeu, SP. }\end{array}$ & 2011 \\
\hline $\begin{array}{l}\text { SANTOS, Crítica a Organização do a dnelson Araújo } \\
\text { dos }\end{array}$ & $\begin{array}{l}\text { Conhecimento do Esporte na Formação em } \\
\text { Educação Física } \\
\text { UEPA }\end{array}$ & 2011 \\
\hline
\end{tabular}

\section{Os diálogos}

Para realizarmos as análises dos estudos selecionados, dialogamos com outros além dos citados acima. Mas, estudos estes, que discutem a "esportivização" no currículo da formação inicial.

Oliveira (1989) apresenta um profundo estudo sobre as disciplinas práticas do curso de EF da Universidade Estadual de Maringá, onde conclui que o conjunto de procedimentos didático-pedagógicos que organizam as aulas "reproduzem e reforçam os aspectos sociais controladores da ordem opressora instituída" (p.252); que "o aprendizado e a prática, pelos participantes, do desporto institucionalizado são tidos como funções fundamentais destas disciplinas" (p.252), resultando na cobrança do gesto técnico como processo de avaliação; que os procedimentos pedagógico-metodológicos nas aulas "caracterizam-se preferencialmente por serem de tipo fechado e sem condições de decisão para os alunos, restando a estes a função de estarem presentes e obedecerem ao plano e as ordens do professor" (p. 253).

Também, é possível observar esta lógica de tratamento das disciplinas esportivas no estudo de Pirolo (1997). Esta autora realizou um estudo com os professores da disciplina acadêmica "Voleibol" em seis universidades do Paraná, concluindo que a maioria dos professores tinha um entendimento de educação caracterizada pela ideia de transmissão de informação e regras sociais para o educando adaptar-se ao sistema social vigente; uma imagem de EF marcada por ideias higienistas e pedagogicistas; um conceito de competência técnico-profissional equivalente ao conhecimento das atividades desportivas (saber-fazer) e de sequências pedagógicas para o ensino dos fundamentos técnicos e táticos do esporte e uma representação de competência política análoga à capacidade para conseguir as condições necessárias à massificação desportiva no país (PIROLO, 1997).

As conclusões de Oliveira (1989) e Pirolo (1997) ajudam a traçar um quadro destas disciplinas e que pouco tem mudado a forma de trabalhar nos últimos trinta anos, como mostram as descrições também encontradas no trabalho de Daolio, quando relata sua própria formação profissional na década de 70:

A formação atual de grande parte dos profissionais de $\mathrm{EF}$, que se dá na maioria dos mais de 150 cursos superiores espalhados pelo Brasil, ainda não consegue tratar o esporte nas suas dimensões históricas, culturais, sociológicas, econômicas, como fenômeno de marketing, etc. A grande quantidade de horas nas disciplinas que tratam o esporte nos cursos de formação profissional em EF ainda é destinada aos aspectos técnicos das modalidades, fazendo com que os alunos, futuros professores, pratiquem os fundamentos esportivos na duvidosa premissa de que basta aos alunos saberem fazer para saberem ensinar futuramente (1998, p. 111-2).

Castellani Filho(1998) aponta que as disciplinas esportivas se restringem a ensinar as técnicas necessárias para se praticar uma determinada modalidade. Abordando o futebol, observa que o conhecimento transmitido visa ensinar a jogar, conhecer as regras, as técnicas e 
as táticas do jogo e transmitir as práticas pedagógicas necessárias para passar este conteúdo adiante.

Não diferentes dessas percepções, estudos de Terra (1997) também coincidem quando o assunto é a forma de trabalhar as disciplinas esportivas. A autora ressalta as disciplinas esportivas:

vem apresentando resultados insatisfatórios, além da falta de propostas no sentido de promover uma formação técnica, científica e filosófica competente, com vistas a um profissional efetivamente compromissado com a construção de uma cidadania crítica, responsável e autônoma. (1997, p.208)

Moreno realizou estudos sobre o ensino do Basquetebol no Ensino Superior. O autor tece considerações sobre os objetivos, conteúdos, aspectos metodológicos e processo avaliativo. Quanto aos aspectos relativos à bibliografia e aos conteúdos, destacamos:

Os conteúdos analisados estão voltados ao basquetebol de competição e a sua influência no perfil do profissional a ser formado pode ser confrontada com a tendência generalista. Desta forma, notamos uma forte inclinação a uma formação técnica e não generalista como é proposto nos documentos. As referências bibliográficas [...] na sua maioria voltada às técnicas e táticas, demonstrando contradição em relação aos objetivos apresentados, já que esses apontam para o basquetebol utilizado como meio educacional (MORENO, 1998, pág. 137)

Para Moreno "muitas disciplinas esportivas mantem ainda um cunho técnico desportivo sem qualquer fundamentação sócio-pedagógica crítica, indicando ausência de reflexão sobre a autonomia e identidade pedagógicas da EF" (1998, p.109).

No mesmo ano, Daólio destaca que os cursos de ensino superior em educação física limitavam a transmitir conteúdos técnicos esportivos e o saber-fazer. Partindo da lógica que se os acadêmicos sabem fazer também saberão ensinar. Relacionar o ensino do esporte com temáticas nas suas dimensões históricas, sociológicas, entre outras dimensões era algo ainda não desenvolvido, pois:

a formação atual de grande parte dos profissionais de educação física, que se dá na maioria dos mais de 150 cursos superiores espalhados pelo Brasil, ainda não consegue tratar o esporte nas suas dimensões históricas, culturais, sociológicas, econômicas, como fenômeno de marketing, etc. A grande quantidade de horas nas disciplinas que tratam o esporte nos cursos de formação profissional em educação física ainda é destinada aos aspectos técnicos das modalidades, fazendo com que os alunos, futuros professores, pratiquem os fundamentos esportivos na duvidosa premissa de que basta os alunos saberem fazer para saberem ensinar futuramente (1998, p. 111-112).

Em estudos mais recentes como de Santos(2011), treze anos depois, ainda encontramos a mesma situação no processo ensino aprendizagem:

[...] essa ideia de que a formação profissional em Educação Física deve privilegiar a execução de habilidades motoras, é denominada concepção esportivista ou tradicional-esportiva e está presente ainda hoje em alguns cursos de formação profissional em educação física (pág.85).

Em outra dissertação, Coutinho (2007) investigou a adoção de métodos de ensino para os esportes coletivos nos cursos de licenciatura em Educação Física. Em sua dissertação buscou verificar o nível declarado de conhecimento de 17 professores em relação aos métodos de ensino para os Jogos Desportivos Coletivos (JDC) e identificar e analisar os motivos da 
adoção ou não adoção dos diferentes métodos de ensino para os JDC pelos professores de disciplinas desportivas. Dentre seus achados, podemos destacar:

praticamente todos estes profissionais afirmaram conhecer e adotar o chamado Método Tradicional, evidenciando-se que o acréscimo de estudos humanistas nos currículos parece não ter apresentado, ainda, consequências na adoção de novas metodologias de ensino. Em contrapartida, apesar da constatação desta adoção maciça do Método Tradicional Tecnicista por parte dos sujeitos da pesquisa, um aspecto que nos chamou a atenção pela sua relevância para nosso estudo, foi à verificação de que 14 dos 17 sujeitos pesquisados (82,5\% do total) disseram também estar adotando outros métodos de ensino além do Método Tradicional (pág. 80).

Infelizmente este estudo não revela como os professores se justificam ao elaborarem suas aulas, adotando ora uma metodologia tecnicista ora outra metodologia. Como adotar metodologias com bases epistemologicamente diferentes numa mesma disciplina? Qual seria o objetivo dessa junção de metodologias? Essas são algumas limitações deste estudo.

Apesar do estudo indicar que a maioria dos professores utilizaram a metodologia tradicional, o mesmo autor ressalta:

\begin{abstract}
Para nós estes dados são muito importantes, pois demonstram que apesar do Método Tradicional Tecnicista ainda estar fortalecido percebe-se que sua adoção única e exclusiva parece estar encerrando seu ciclo, acreditamos e esperamos que realmente esteja acontecendo uma mudança de paradigma a fim de que possa ocorrer alguma evolução positiva na Educação Física no país (COUTINHO, 2007, pág. 101).
\end{abstract}

\title{
Propostas do ensino do esporte na graduação em educação física: campo de estudo, ciclo, agrupamentos...
}

Com estas preocupações, estudiosos nesta área tem proposto sugestões como também desenvolvido experiências, no sentido de superar as práticas tradicionais do ensino do esporte na graduação em Educação Física. No conjunto destas propostas, é possível identificar alguns princípios de intervenção didático-pedagógicos similares para o ensino das disciplinas esportivas na universidade.

Entre outros princípios, podemos destacar o seguinte: a) a lógica de centrar a formação dos futuros professores no diálogo e na reflexão sobre o fenômeno esportivo, seu processo de ensino e sua implicação sobre a formação dos sujeitos; b) procurar fazer com que os acadêmicos compreendam o esporte como uma construção cultural, social e historicamente localizada, e, por isso, factível de transformação; c) dar centralidade à compreensão do processo de ensino-aprendizagem como um ato político e, necessariamente, engajado num projeto social (por ação ou por omissão) e não como uma intervenção neutra.

Outra concepção do ensino do esporte na formação inicial sobre os estudos de Colavolpe (2005). A proposta foi inicialmente anunciada em sua dissertação de mestrado intitulada "O esporte como conteúdo nos cursos de formação de professores: Realidades e possibilidades". Nela o autor apresenta a crítica ao currículo organizado por modalidades e apresenta uma organização por ciclos. $\mathrm{O}$ mesmo autor dá continuidade à discussão do esporte na formação e na possibilidade de organização por ciclos em sua tese de doutorado, publicada em 2010: "Sociedade, Educação e esporte: A teoria do conhecimento e o esporte na formação de professores de educação física".

Colavolpe (2005) ressalta o ensino do esporte em formato de ciclos como uma possibilidade de proporcionar aos alunos - um novo eixo articulador dos tempos, espaços e conteúdos a serem vivenciados em atividades de ensino, pesquisa e extensão do ensino superior. E tem como perspectiva a atuação em conjunto dos professores responsáveis pela aprendizagem nos ciclos 
Outro estudo que merece destaque, são as análises do trato do esporte no ensino superior realizadas por Gonzales(2004). O estudo discute uma proposta de disposição do esporte na grade curricular implantada no Curso de EF da Universidade Regional do Noroeste do Estado de Rio Grande do Sul, Unijui, (CEFU). O autor deixa claro nesta proposta que o esporte se torna um campo de estudo, buscando (como em outros estudos) superar a ideia do esporte estruturado como modalidade esportiva. É importante esclarecer o que diz o projeto político-pedagógico do CEFU acerca do esporte. O tema Esporte é constituído em 11 componentes curriculares: Estruturas dos esportes I e II; Etapas da formação Esportiva; Metodologia do Ensino dos Esportes I, II e III; Pedagogia do Esporte I e II; Planejamento de Formação Esportiva; Dimensões Psicossociais do Esporte; Dimensões Histórico-sociais do Esporte.

Neste sentido, Gonzales alerta:

A formação acadêmica no processo ensino-aprendizagem do esporte tem compromisso de ir além da instrumentalização técnica, o que tem sido historicamente caracterizado como ensino do esporte na universidade. É imprescindível a formação pedagógica mais ampliada para entender o esporte na sua complexidade, numa perspectiva crítica, como um elemento emancipatório, como espaço humanizado (2004, p. 220).

Nesta mesma maneira de perceber o esporte no ensino superior, o curso de graduação em Educação Física da UFF elaborou o esporte no currículo em forma de grupos de disciplinas. Castro e Almeida (2009) destacam esse assunto citando:

Como o nosso objetivo é ensinar os esportes com fim educativo, procurando realçar suas características lúdicas, procuramos minimizar a importância da técnica até mesmo quando criamos os nomes das disciplinas. Nesse rol, incluímos Esporte e Jogo I, II, III e IV. Entendemos que agrupando os esportes diminuiremos a importância do aperfeiçoamento técnico, pois com a carga horária disponível para uma disciplina desenvolvemos vários esportes. O acréscimo da palavra jogo ao lado do termo esporte tem como objetivo dizer que o esporte deve ter um caráter lúdico (p. 06).

Neste exemplo, as disciplinas "Esporte e Jogo I, II, III e IV" abordam a discussão contemporânea dos significados para esporte e jogo, ao mesmo tempo em que os alunos experimentam e tratam pedagogicamente um conjunto de práticas corporais que não estão organizadas no predominante "Basquete", "Vôlei", "Futebol" etc.

Sabemos que nenhum currículo conseguirá compreender todas as modalidades esportivas do mundo, pois o esporte, como expressão da cultura, será sempre dinâmico (DAÓLIO, 1998).

Através destes estudos apresentados, percebemos que a produção do conhecimento a respeito da temática do esporte no ensino superior em educação física vem contribuindo, através de propostas de (re)formulação de conteúdo, para uma formação discente mais reflexiva. É neste contexto de formação que o esporte deve ser compreendido. Compreendê-lo como um fenômeno social, dinâmico e relevante, ampliando o entendimento desta manifestação cultural tão presente na modernidade, refletindo sobre possibilidades do processo ensino aprendizagem no ensino superior.

\section{Considerações Finais}

Somente a mudança dos nomes das disciplinas, sem um esforço coletivo dos atores que fazem parte do processo, ou mesmo, a aceitação passiva de literaturas denominadas 
"manuais" de exercícios, resultando em práticas reprodutivistas, são alguns dos cuidados que devemos ter sobre o ensino do esporte no contexto do ensino superior (GRAÇA, 1999).

Fica claro o esforço em reestruturar o esporte no ensino superior através de modelos que buscam superar o modelo tradicional e tecnicista de ensiná-lo. A mudança em agrupar as modalidades esportivas em blocos de disciplinas, com o intuito de torná-las em um campo de estudo, para poder ensinar o esporte numa maneira mais contextualizada parece ter uma contribuição significativa.

Realmente não sabemos se este modelo ainda é o ideal (se é que temos algum modelo ideal), mas fazer do esporte muito mais um processo de mediação do que um fim em si mesmo, já é um excelente passo para a contextualização do seu ensino.

Neste sentido, acreditamos que mais estratégias de ensinar o esporte devam surgir, na perspectiva de construir uma nova identidade no trato do esporte no ensino superior, adequando a estrutura curricular às novas demandas de formação do Licenciado em Educação Física, buscando uma formação mais crítica e reflexiva.

\title{
SPORT AS A TREATMENT COURSE OF UNDERGRADUATE CURRICULUM IN PHYSICAL EDUCATION
}

\begin{abstract}
This study aims to investigate, through a literature review, as the sport is treated as content in undergraduate courses in Physical Education. The methodology used is qualitative perspective with bibliographical character that according to Gil (1995), among other things involves the bibliographical and documentary. Of the selected studies all point to overcome the so-called "sportivization" curriculum. Thus, this study is justified by contributing to the pedagogical practice of sports in higher education. We realize that new strategies to teach the sport have emerged in the perspective of building an identity in the treatment of sports in higher education, seeking a more reflective of academic training in Physical Education. Keywords: Sports. Curriculum. Training.

\section{EL DEPORTE COMO UN CURSO DE TRATAMIENTO DE PLAN DE ESTUDIOS LICENCIATURA EN EDUCACIÓN FÍSICA}

\section{Resumen}

Este estudio tiene como objetivo investigar, a través de una revisión de la literatura, ya que el deporte se considera como contenido en los cursos de licenciatura en Educación Física. La metodología utilizada es la perspectiva cualitativa con carácter bibliográfico que, según Gil (1995), entre otras cosas implica el bibliográfico y documental. De los estudios seleccionados apuntan a superar la denominada "sportivization" plan de estudios. Por lo tanto, este estudio se justifica por la contribución a la práctica pedagógica del deporte en la educación superior. Nos damos cuenta de que las nuevas estrategias para enseñar el deporte se han convertido en la perspectiva de construir una identidad en el tratamiento del deporte en la educación superior, en busca de una más reflexiva de la formación académica en Educación Física. Palabras clave: Deportes. Programas de estudios. De formación. 


\section{Referências}

ANDRADE FILHO, N. F. Sobre o conhecimento que orienta a formação em Educação Física brasileira. Dissertação (Mestrado em Educação Física). Universidade Gama Filho: RJ, 2001.

ALVIANO JR., Wilson. Formação Inicial em Educação Física: análises de uma construção curricular. 2011. 270 f. Tese (Doutorado). Faculdade de Educação, Universidade de São Paulo, São Paulo, 2011.

BENITES, Larissa Cerignoni; NETO, Samuel de Souza; HUNGER, Dagmar. O processo de constituição histórica das diretrizes curriculares na formação de professores de Educação Física. Universidade Estadual Paulista. Revista Educação e Pesquisa, São Paulo, v.34, n.2, p. 343-360, maio/ago. 2008.

CASTELLANI FILHO, L.(1998) Política educacional e educação física. SP: Autores Associados.

CASTRO, W. L. de; ALMEIDA, P. A. C. de. A Licenciatura em Educação Física na Universidade Federal Fluminense: uma trajetória de enfrentamento. Anais do XVI CONBRACE e II CONICE. Salvador, 2009. Disponível em: <http://cbce.tempsite.ws/congressos/index.php/CONBRACE/XVI/paper/view/1533/673> Acesso em: 28 de junho de 2012.

COLAVOLPE, Carlos Roberto. O Esporte como conteúdo nos cursos de formação de professores: realidade e possibilidades. Dissertação (Mestrado) 2005 - Universidade Federal da Bahia. Faculdade de Educação, Salvador, 2005.

Sociedade, Educação e Esporte: A Teoria do Conhecimento e o Esporte na Formação de Professores de Educação Física. 234 f. Tese (Doutorado) - Universidade Federal da Bahia. Faculdade de Educação, Salvador, 2010.

COUTINHO, Nilton Ferreira. Conhecimento e aplicação de métodos de ensino para os jogos esportivos coletivos na formação profissional em educação física. 109 f. Dissertação (Mestrado em Educação Física) - Universidade São Judas Tadeu, São Paulo, 2007.

DAOLIO, J. Fenômeno social esporte na formação profissional em educação física. Revista da Educação Física/UEM n9, v.1, p. 111-115, 1998.

FRIGOTTO, G. Educação e Crise no Trabalho: perspectivas de final de século. Petrópolis: RJ. Vozes, 1998.

GENTILLI, P. (org). Globalização Excludente: desigualdades, exclusão e democracia na nova ordem mundial. Petrópolis: vozes, 2000.

GIL, Antonio C. Métodos e Técnicas de Pesquisa Social. São Paulo: Atlas, 1995.

GONZALEZ, Fernando Jaime. O estudo do esporte na formação superior em Educação Física: construindo novos horizontes. Movimento, Porto Alegre, v. 10, n. 1, p. 213-229, jan./abr. 2004. 
Potencialidades e limites de uma proposta alternativa de estudo do esporte na formação superior em educação física: Olhares de professores e acadêmicos. Disponível em: <http://www.cbce.org.br/cd/resumos/203.pdf> Acesso em: 28 out. 2009.

GRAÇA, A. Conhecimento do professor de educação física. In: BENTO, J.; GARCIA, R.; GRAÇA, A. Contexto da pedagogia do desporto. Porto: Livros Horizonte, 1999.

MELO, Fábio Antonio Tenório de. O futsal como disciplina curricular nos cursos de graduação em Educação Física no Distrito Federal. 2002. Dissertação (Mestrado em Educação Física), Faculdade de Educação Física, Universidade Católica de Brasília, Brasília, 2002.

MOLINA NETO, V. Uma experiência de ensino do futebol no currículo de licenciatura em Educação Física. Revista Movimento, Porto Alegre, ano 2 n. 2, 1995 p.29-37, 1995.

MOLINA NETO, Vicente. Uma experiência de ensino do futebol no currículo de licenciatura em Educação Física. Revista Movimento, Porto alegre, v. 2, n. 12, p. 53-62, 2000.

MORENO, José Carlos de Almeida. A disciplina basquetebol e a formação de professores de educação física. 1998. 149 f. Dissertação (Mestrado em Educação Física), Faculdade de Educação Física, Universidade Estadual de Campinas, Campinas, 1998.

NASCIMENTO, Juarez Vieira do Nascimento; RAMOS, Valmir; MARCON, Daniel; SAAD, Michél Angillo; COLLET, Carine. Formação acadêmica e intervenção pedagógica nos esportes. Motriz, Rio Claro, v.15 n.2 p.358-366, abr./jun. 2009.

OLIVEIRA, A. A. B. Análise critica do currículo das disciplinas práticas do curso de educação física da universidade estadual de Maringá. Revista da Educação Física/UEM, Vol. 0, No 1, 1989.

PIRES, G. D. L.; NEVES, A. O trato com o conhecimento esporte na formação em Educação Física: possibilidades para a sua transformação didático-pedagógica. In: KUNZ, E. (org.) Didática da Educação Física 2. Ijuí: Unijuí, 2002.

PIROLO, A. L. A disciplina de voleibol nos cursos de licenciatura em Educação Física do Paraná: Processo de conhecimento crítico-reflexivo? In: COSTA, V. L. M. Formação profissional universitária em educação física. Rio de Janeiro: Editora Central da Universidade Gama Filho, 1997.

REZER, Ricardo. O ensino do esporte na Formação de professores - Reflexões didáticopedagógicas... Anais do XVI Congresso Brasileiro de Ciências do Esporte e III Congresso Internacional de Ciências do Esporte. Salvador, 20 a 25 de Setembro de 2009.

SANTOS, Adnelson Araújo dos. Crítica a organização do conhecimento do esporte na formação em Educação Física. Dissertação (Mestrado em Educação) - Universidade do Estado do Pará. Belém, 2011.

SILVA, Tomaz Tadeu da. Documentos de identidade - Uma introdução às teorias do 
currículo. Belo Horizonte: Autêntica, 1999.

TERRA, Dinah V. Ensino crítico-participativo das disciplinas técnico-desportivas nos cursos de licenciatura em Educação Física: análise do impacto de um projeto de ensino no handebol. In: COSTA, Vera L. (Org.). Formação profissional universitária em Educação Física. Rio de Janeiro: Ed. Central da Gama Filho, 1997.

TREPTOW, Anahy Garcia. A formação do professor de Educação Física no Pará: o que revela a história do currículo do Curso de Educação Física na Universidade Estadual do Pará? Dissertação (Mestrado) - Universidade Federal do Pará, Instituto de Ciências da Educação, Programa de Pós-Graduação em Educação, Belém, 2008.

Recebido em: 10/02/2015

Revisado em: 16/01/2016

Aprovado em: 10/08/2016

Endereço para correspondência:

edson.junior@ifrj.edu.br

Edson Costa Farret

Instituto Federal do Rio de Janeiro

Rua José Augusto Pereira dos Santos, s/n

Neves

24425-004 - São Gonçalo, RJ - Brasil 